\title{
Atualizações sobre $\beta$-hidroxi- $\beta$-metilbutirato: suplementação e efeitos sobre o catabolismo de proteínas
}

\author{
New findings on $\beta$-hydroxy- $\beta$-methylbutyirate: \\ supplementation and effects on the protein catabolism
}

Everson Araújo NUNES'

Luiz Cláudio FERNANDES ${ }^{1}$

o $\beta$-hidroxi- $\beta$-metilbutirato, metabólito do aminoácido leucina, vem sendo utilizado como suplemento alimentar, em situações específicas, com o intuito de aumentar ou manter a massa isenta de gordura. Os relatos dos efeitos do $\beta$-hidroxi- $\beta$-metilbutirato em estudos recentes fizeram crescer as expectativas sobre sua utilização em casos patológicos. Também foram demonstrados melhores resultados, quando da sua ingestão, no treinamento de força em indivíduos iniciantes e em idosos. Em humanos o $\beta$-hidroxi- $\beta$-metilbutirato tem sido usado como agente anti-catabólico, e em modelos animais foi demonstrado ser eficaz em inibir a atividade de vias proteolíticas em células musculares de indivíduos caquéticos in vitro e in vivo. Os mecanismos participantes desses processos envolvem: a inibição da atividade do sistema ubiquitina proteossoma ATP-dependente, a inibição de vias de sinalização com participação da proteína quinase C-alfa e a diminuição da concentração citoplasmática do fator nuclear - kappa B livre, eventos relacionados ao decréscimo da proteólise em células musculares.

Termos de indexação: Leucina. Metabolismo. Suplementação alimentar.

A B S T R A C T

The leucine metabolite $\beta$-hydroxy- $\beta$-methylbutyrate has been used as a nutritional supplement in specific situations to prevent losing or to increase lean mass. Recent studies showed interesting results of $\beta$-hydroxy$\beta$-methylbutyrate supplementation in certain disease states. Better results have also been demonstrated when it is taken by starters or old individuals doing strength training. In humans, $\beta$-hydroxy- $\beta$-methylbutyrate has been used as an anticatabolic agent and in animal models it has been demonstrated to be effective in inhibiting the activity of the proteolytic pathways in muscle cells of extremely weak individuals in vivo and in

\footnotetext{
$1{ }^{1}$ Universidade Federal do Paraná, Centro Politécnico, Departamento de Fisiologia, Laboratório de Metabolismo Celular, Setor de Ciências Biológicas. Caixa Postal: 190-31, Jd. Américas, 81531-980, Curitiba, PR, Brasil. Correspondência para/Correspondence to: E.A. NUNES. E-mail: <eanunes@ufpr.br>.
} 
244 E.A. NUNES \& L.C. FERNANDES

vitro. The mechanisms that participate in this process involve: inhibition of the ATP-ubiquitin-proteasome pathway, inhibition of the signalization pathways involving protein kinase C-alpha and reduction of the cytoplasmatic concentration of free nuclear factor kappa- $B$, events that are associated with the reduction of proteolysis in muscle cells.

Indexing terms: Leucine. Metabolism. Supplementary feeding.

\section{N T R O D U Ç Ã O}

Há várias categorias de suplementos nutricionais comercializadas atualmente. Entre elas estão aquelas para ganho de massa muscular, perda de gordura corporal, os energéticos etc. ${ }^{1}$. Nissen \& Sharp ${ }^{2}$ apontaram o $\beta$-hidroxi- $\beta$-metilbutirato (HMB) como um dos suplementos comercializados com eficácia apoiada por vários estudos publicados. Seu mecanismo de ação proposto é o efeito anti-catabólico, o qual, como conseqüência, proporciona aumento da massa isenta de gordura. Em humanos foram obtidos resultados variados, quando da suplementação com HMB em condições de estresse patológico, de exercício ou de mudanças fisiológicas decorrentes do envelhecimento, cujas respostas diferenciadas foram dependentes do protocolo experimental utilizado.

\section{Influência da leucina e seus metabólitos sobre o metabolismo protéico}

Entre as variáveis que induzem mudanças no metabolismo das células e nos tecidos corporais estão o exercício físico, o envelhecimento e o desenvolvimento de doenças. Além destas muitos componentes dietéticos possuem efeitos fisiológicos. De longa data sabe-se que a ingestão de refeições contendo proteínas promove aumento na taxa de síntese protéica corpórea total, bem como a supressão da degradação protéica ${ }^{3-5}$. Este efeito anabólico pode ser atribuído, em parte, ao aumento do aporte de aminoácidos para a musculatura esquelética. Adicionalmente, aminoácidos específicos podem funcionar como moléculas sinalizadoras interferindo no turnover protéico. Em particular, o aminoácido de cadeia ramificada leucina, possui a habilidade de estimular, independentemente, a síntese protéica in vitro. A leucina regula o turnover protéico por mecanismos que não envolvem somente sua participação como precursor para síntese protéica e sua participação ocorre de maneira independente a qualquer alteração no quadro hormonal6-8.

O efeito regulatório da leucina em estimular a síntese e/ou inibir a degradação protéica, em tecidos isolados, tem sido confirmado em vários estudos ${ }^{6}$. No entanto, o mecanismo pelo qual esse aminoácido altera o turnover protéico ainda não está bem descrito. Inibidores da transaminação da leucina inibem seu efeito sobre o catabolismo protéico, mas não afetam seu efeito estimulatório sobre a síntese protéica. Isto sugeriu, fortemente, que o efeito da leucina sobre a degradação protéica é mediado por algum metabólito. Um metabólito da leucina, candidato a promotor do efeito inibitório sobre o catabolismo protéico, é o $\beta$-hidroxi- $\beta$-metilbutirato (HMB) ao lado do $\alpha$-ceto-isocaproato (CIC ou KIC $)^{9,10}$. Ostaszewski et al. ${ }^{9}$ incubaram músculos de aves e ratos na presença de HMB e encontraram aumento da síntese protéica em $20 \%$ e redução do catabolismo protéico em, aproximadamente, 80\%. Alguns autores propõem que, em situações de estresse, tanto animais quanto humanos não sintetizam quantidades de HMB necessárias para suprir a demanda tecidual ${ }^{11}$.

\section{Suplementação com CaHMB \\ Doses utilizadas, segurança e efeitos adversos}

O sal de cálcio do ácido $\beta$-hidroxi- $\beta$-metilbutírico forma um monohidrato com fórmula química $\mathrm{Ca}\left(\mathrm{C}_{5} \mathrm{H}_{9} \mathrm{O}_{3}\right)_{2} \cdot \mathrm{H}_{2} \mathrm{O}$ (CaHMB monohidrato), no qual o elemento cálcio corresponde a 13,7\% do peso molecular. Este composto, quando colocado em 
água, dissolve-se rapidamente formando uma solução saturada a $27 \%(\mathrm{p} / \mathrm{p})$ a $20^{\circ} \mathrm{C}^{12}$. A adição de HMB a suplementos ou a comercialização do produto puro se faz, então, na forma de CaHMB monohidrato, o qual pode ser encontrado em formulações em pó, cápsulas e adicionado a barras protéicas ou substitutas de refeição.

Em sua maioria, os trabalhos envolvendo suplementação com HMB utilizam doses entre 1-3g/indivíduo/dia², porém há estudos com doses de $6 \mathrm{~g} / \mathrm{dia}$ ou ainda ministradas de acordo com o peso dos voluntários. Exemplos de doses encontradas em alguns estudos podem ser $38 \mathrm{mg} / \mathrm{kg} / \mathrm{dia}$ e $76 \mathrm{mg} / \mathrm{kg} / \mathrm{dia}^{13-15}$. Estes valores correspondem a, aproximadamente, 3 e $6 \mathrm{~g} / \mathrm{dia}$ para indivíduos com peso próximo a $80 \mathrm{~kg}$. Em estudo que demonstrou efeito positivo da suplementação com HMB sobre a massa isenta de gordura, a utilização de $6 \mathrm{~g} / \mathrm{dia}$ não promoveu resultado significativamente diferente, quando comparado ao que usou dose de $3 \mathrm{~g} / \mathrm{dia}^{14}$.

Nas doses preconizadas na literatura, a suplementação com HMB não trouxe nenhum efeito colateral deletério aparente ${ }^{15}$. Estudos em modelos animais não demonstraram efeito tóxico com doses maiores que $100 \mathrm{~g} /$ dia. Recentemente, Baxter et al. ${ }^{16}$ demonstraram, em estudo com ratos, que dietas com até $5 \%$ de HMB por 91 dias não provocaram mudança em nenhum dos 18 parâmetros hematológicos nem nos 17 parâmetros bioquímicos analisados, assim como não provocou alteração perceptível nos pesos e na aparência dos principais órgãos e algumas glândulas dos indivíduos de ambos os sexos. A suplementação de HMB em humanos não causou nenhum efeito colateral após suplementação com doses altas por mais de 7 semanas ${ }^{11}$. Estudos clínicos por períodos de até 12 semanas não demonstraram nenhum potencial efeito tóxico ${ }^{11,17}$. Entre estes estudos foram realizados levantamentos com questionários objetivando a pesquisa de efeitos adversos, porém nada foi encontrado. Após a ingestão de $\mathrm{HMB}$ a única variável modificada agudamente nos parâmetros metabólicos dos indivíduos foi a concentração plasmática do próprio HMB. A excreção de hormônios esteróides, as funções hepáticas e as renais também não tiveram nenhuma alteração após duas semanas de ingestão de $3 \mathrm{~g} / \mathrm{HMB} / \mathrm{dia}^{13}$. Crowe et al. ${ }^{18}$ relataram que atletas de rugbi que utilizaram 3g/dia de HMB por seis semanas não apresentaram efeito adverso à saúde. Contudo, estudos adicionais em humanos e, principalmente, em populações especiais, como grávidas e crianças, devem ser conduzidos antes de qualquer recomendação com maior abrangência.

\section{Cinética após ingestão}

Um dos destinos da molécula de HMB após sua síntese ou ingestão é sua excreção na urina ${ }^{19}$. Valores obtidos em estudos com suínos e ovinos suplementados relataram excreção de até um terço do $\mathrm{HMB}^{20}$, enquanto que em humanos suplementados com HMB este valor alcançou $50 \%$ da dose administrada ${ }^{11}$.

A concentração plasmática basal do HMB no estado pós-absortivo em humanos e animais é, aproximadamente, zero ${ }^{19}$. A ingestão de $50 \mathrm{~g}$ de leucina ou $2 \mathrm{~g}$ de HMB pode aumentar suas concentrações plasmáticas em até 6 vezes. Em adição, alguns protocolos, avaliando a meia-vida do HMB em suínos e ovinos, demonstraram que após a ingestão de $2 \mathrm{~g}$ de HMB a meia-vida foi de, aproximadamente, 2 horas ${ }^{11}$. Um recente estudo em humanos ${ }^{19}$ investigou a cinética do HMB após ingestão de $1 \mathrm{~g}$ ou $3 \mathrm{~g}$ do mesmo. Os resultados deste estudo demonstram que as concentrações plasmáticas de HMB atingem pico de, aproximadamente, $120 \mathrm{nmol} / \mathrm{mL}$ após $2 \mathrm{~h}$ da ingestão de $1 \mathrm{~g}$, enquanto pico em torno de $480 \mathrm{nmol} / \mathrm{mL}$ foi atingido em apenas $1 \mathrm{~h}$ após a ingestão de $3 \mathrm{~g}$ de HMB. A meia-vida plasmática foi de, aproximadamente, $2,3 \mathrm{~h}$, enquanto a excreção na urina foi dependente da dose, 14\% para a de $1 \mathrm{~g}$ e $29 \%$ para a de $3 \mathrm{~g}$. Quando HMB é ingerido juntamente com glicose, foi demonstrado que esse procedimento é capaz de provocar interferência na cinética do HMB; houve atraso, de, aproximadamente, $1 \mathrm{~h}$, e diminuição no pico 
de HMB plasmático. Ao mesmo tempo existiu pequeno aumento da meia-vida plasmática, o que pode estar relacionado à leve diminuição na excreção urinária de HMB. Outra constatação dos autores neste estudo foi a provável ausência de interferência da insulina na cinética do HMB.

Estudos adicionais com outros macronutrientes devem ser formulados para o total entendimento das variáveis com possível participação na cinética do HMB, a ingestão de refeições mistas contendo proteínas, lipídeos e fibras, certamente, pode influenciar o comportamento cinético do HMB no organismo humano.

\section{Suplementação em indivíduos sedentá- rios e treinados}

\section{Aumento de massa isenta de gordura}

A real eficácia da suplementação com HMB sobre parâmetros de composição corporal ainda está por ser comprovada. Vários estudos envolvendo exercício de força e suplementação de HMB visando, a melhorar os resultados do treinamento, foram realizados nos últimos 10 anos, porém resultados conflitantes foram gerados. A administração de 1,5 ou $3 \mathrm{~g}$ de HMB/dia, por três semanas a indivíduos jovens que realizavam três sessões de treinamento de força por semana, com duração de 90 minutos, foi capaz de aumentar a força e a massa isenta de gordura mensurada por condutividade elétrica corporal total. O grupo que recebeu 3g/dia apresentou resultados superiores ao que recebeu 1,5g/dia. Foram avaliados ainda marcadores de estresse muscular (creatina fosfoquinase e lactato desidrogenase plasmática) e degradação protéica (3-metil-histidina), os quais se revelaram reduzidos a partir da segunda semana nos grupos suplementados. Neste mesmo estudo, outros indivíduos do sexo masculino ingeriram $3 \mathrm{~g}$ de HMB/dia ou placebo por sete semanas. Seis dias por semana os voluntários faziam treinamento de força por duas a três horas diárias. O grupo suplementado com HMB apresentou aumento significativo da força no exercício de supino reto acompanhado de, aproximadamente, $2 \mathrm{~kg}$ de massa isenta de gordura, quando comparado ao grupo placebo ${ }^{21}$.

Estudo seguindo modelo duplo-cego utilizando indivíduos idosos, homens e mulheres na faixa dos 70 anos de idade, que faziam exercício de força, que eram suplementados com HMB na dose de 3g/dia, demonstrou haver aumento significativo na massa isenta de gordura desses indivíduos, quando avaliada por tomografia computadorizada e absormetria de raio $X$ de dupla energia ${ }^{22}$. Este achado é corroborado pelos estudos de Panton et al. ${ }^{23}$ que também encontraram aumento na resposta ao exercício de força em grupo de homens e mulheres que receberem HMB por quatro semanas. Nesses estudos não houve o cuidado de avaliar a repercussão dos resultados sobre a qualidade de vida dos participantes, contudo os grupos suplementados demonstraram sofrer influência da suplementação em sua composição corporal.

Apesar dos resultados positivos em indivíduos suplementados com HMB iniciantes de treinamento de força, o mesmo parece não ocorrer quando a suplementação com HMB é feita em pessoas consideradas treinadas ou atletas de competição. Estudos realizados nos últimos sete anos, que investigaram os efeitos ergogênicos do HMB em atletas e praticantes de atividade física, demonstraram que em indivíduos treinados e em atletas de potência de elite, a ingestão de HMB não aumentou a massa magra ${ }^{24-26}$ ou a capacidade anaeróbia ${ }^{27}$. O HMB também parece não afetar os marcadores de catabolismo ou a integridade da membrana muscular em indivíduos bem treina$\operatorname{dos}^{25,26,28}$. Ransone et al. ${ }^{25}$ suplementaram jogadores de futebol com 3g/dia de HMB e relataram não observar nenhum efeito sobre parâmetros de força ou composição corporal; e afirmam que existem poucas evidências clínicas que sustentem a utilização de HMB com o objetivo de melhorar o desempenho de atletas. Esses achados foram corroborados posteriormente por Hoffman et al. ${ }^{29}$, que verificaram que 10 dias de suplementação com HMB (3g/dia) não modificaram parâmetros 
de estresse e lesão muscular causados pelo treinamento da pré-temporada da liga de futebol.

Em resumo, se o objetivo buscado for verificar o efeito sobre variáveis de composição corporal, a suplementação com HMB é plausível apenas quando se tratar de indivíduos sadios em início de programa de treinamento ou idosos. O incremento de parâmetros relacionados diretamente à melhora do desempenho e da performance em atletas ainda está por ser comprovado.

\section{Suplementação com HMB em idosos e situações hipercatabólicas}

\section{Efeitos sobre a massa isenta de gordura e proteólise muscular.}

Estratégia com grande potencial sobre situações de catabolismo muscular intenso é a utilização de suplementação nutricional direcionada para a estimulação da síntese protéica ou a redução da quebra de proteínas ${ }^{30}$. Alguns estudos em humanos indicam que o HMB pode inibir significativamente o aumento da proteólise induzida pelo exercício, mensurada pela concentração de 3-metilhistidina na urina, assim como evitar aumento da concentração sérica de marcadores de lesão muscular decorrente do exercício de endurance ${ }^{31}$. Em adição, o HMB demonstrou ser capaz de prevenir a excessiva proteólise durante o estresse metabólico ${ }^{10,32-33}$ e aumentar o ganho de massa muscular tanto em homens quanto em mulheres idosos que fazem exercício físico ${ }^{23,30}$, bem como em modelos animais ${ }^{34}$.

Em mulheres idosas, a suplementação diária com HMB, arginina e lisina por 12 semanas, alterou positivamente alguns parâmetros de funcionalidade, força, massa magra e síntese protéica, sugerindo que a estratégia de nutrição direcionada tem a habilidade de afetar a saúde muscular. Na $3^{\mathrm{a}}$ idade as mulheres podem apresentar perda de $1,5 \%$ de massa magra por ano, por razões multifatoriais ${ }^{30}$. Em pacientes com AIDS e câncer , a suplementação com HMB demonstrou também melhorar o perfil emocional dos indivíduos ${ }^{32-33}$.
Clark et al. ${ }^{33}$, May et al. ${ }^{32}$ e Marcora et al. ${ }^{35}$ utilizaram $\mathrm{HMB}$ em conjunto com arginina e glutamina, com o objetivo de tentar reverter o quadro de perda muscular esquelética observada em pacientes com artrite reumatóide, câncer e síndrome da imunodeficiência adquirida (AIDS), respectivamente. Com exceção do trabalho de Marcora et al. ${ }^{35}$, a suplementação mostrou ser eficaz em promover ganho de massa muscular esquelética, quando comparada ao placebo. Nesses trabalhos os autores atribuíram ao aumento da massa muscular o efeito anti-catabólico do HMB associado ao aumento da síntese protéica, causado pelos aminoácidos glutamina e arginina. Contudo, os modelos utilizados não possibilitam afirmar o real efeito anti-catabólico específico do HMB. Kuhls et al. ${ }^{36}$ tiveram o cuidado de testar os efeitos da suplementação com HMB em conjunto com arginina e glutamina e isoladamente para indivíduos com trauma em estado crítico. Nestes pacientes, o HMB promoveu significativa melhora no balanço nitrogenado, quando em comparação com o grupo placebo $(-4,3 \mathrm{~g} / \mathrm{d}$ vs. $-8,9 \mathrm{~g} / \mathrm{d})$.

Essas observações levantam a hipótese de possível ação do HMB sobre vias de sinalização intracelulares específicas, responsáveis pelo metabolismo protéico nas células musculares.

São três as vias responsáveis pelo catabolismo das proteínas no músculo esquelético: sistema lisossomal, o qual é responsável, predominantemente, pela quebra de proteínas extracelulares, como os receptores de membrana ${ }^{37}$; sistema citosólico ativado pelo cálcio independente de ATP, o qual pode representar papel importante na destruição tecidual, na necrose e na autólise ${ }^{38}$; e sistema ubiquitina proteossoma ATP-dependente, o qual se acredita ser o responsável pela quebra do conjunto de proteínas intracelulares no músculo esquelético. O sistema ubiquitina proteossoma ATP-dependente é responsável pela degradação de proteínas musculares em situações de estresse fisiológico ${ }^{37}$. Nesse sistema, proteínas são marcadas para degradação pela ligação com a ubiquitina, o que requer a atividade de três enzimas. $A$ proteína poliubiquitinada é, então, degradada em 
um complexo, formado por multi-subunidades, denominado proteossoma 26S. Esse complexo é formado por três porções, duas denominadas 195 nas extremidades e uma central, conhecida como 20S. A porção 20S, a partir da qual ocorre a proteólise, é estruturada em forma de tubo constituído por quatro anéis, dois $\alpha$ nas extremidades e dois $\beta$ na região central ${ }^{39}$. O proteossoma libera pequenos oligopeptídeos contendo de seis a nove resíduos de aminoácidos, que são rapidamente degradados a aminoácidos pelas peptidases citosólicas ${ }^{40}$.

Quando a proteólise, por intermédio do sistema ubiquitina proteossoma, está acelerada na musculatura esquelética, geralmente há aumento paralelo da produção de mRNAs das enzimas desta via ${ }^{37}$. Moléculas que estimulam o catabolismo de proteínas musculares aumentam a produção das subunidades do proteossoma 26S. Inibindo a expressão de uma única subunidade do proteossoma, o número de proteossomas fica diminuído, bem como a atividade proteolítica e a degradação protéica ${ }^{38}$. Smith et al. ${ }^{41}$ demonstraram, em experimentos in vitro, que o HMB tem a capacidade de diminuir a expressão de genes do sistema ubiquitina proteossoma ATP-dependente induzida por fatores proteolíticos em miotúbulos de roedores, o que acarretou em decréscimo da proteólise muscular. Resposta esta que também foi observada em estudo posterior ex vivo, preservando a massa muscular de camundongos caquéticos suplementados com doses maiores que $0,125 \mathrm{~g} / \mathrm{kg}$ de $\mathrm{HMB}^{10}$.

Em poucas palavras, a suplementação com HMB em situações especiais de hipercatabolismo, ou em indivíduos idosos, parece produzir efeitos significativos que podem, potencialmente, servir de estratégia terapêutica, paralela a outras terapias, visando à manutenção da massa isenta de gordura dos indivíduos e melhora do prognóstico. Estudos adicionais devem ser planejados com o objetivo de averiguar a relação entre os efeitos da suplementação com HMB sobre a massa magra e variáveis ligadas ao quadro clínico do indivíduo ou a sua qualidade de vida.

\section{Influência do HMB sobre vias de sinalização intracelular}

Smith et al. ${ }^{42}$ demonstraram que o $\mathrm{HMB}$ pode inibir a atividade da proteína quinase $C-\alpha$ ( $\mathrm{PKC} \alpha$ ) em miotúbulos C2C12 in vitro, a qual pode estar relacionada com a diminuição da atividade e a expressão de componentes do sistema ubiquitina proteossoma ATP-dependente. Em estudo posterior, Smith et al. ${ }^{10}$, relataram haver diminuição da expressão das subunidades $\alpha$ e $\beta$ da porção 20 e da proteína p42 da porção 19S, após suplementação com HMB. Em adição, o HMB demonstrou ter a habilidade de bloquear a ativação da PKC induzida pelo fator indutor de proteólise (PIF), molécula encontrada em concentrações aumentadas em indivíduos com câncer em estado de caquexia. Essas observações ajudariam a explicar a inibição da expressão do sistema ubiquitina proteossoma ATP-dependente e a subseqüente redução na degradação protéica ${ }^{10,41}$.

A PKC $\alpha$ parece ter participação importante no processo de indução da expressão do sistema ubiquitina proteossoma pelo PIF. Esta expressão foi bloqueada com a utilização de inibidores de PKC e após a transfecção de genes dominante negativo para PKC $\alpha$ em miotúbulos, os quais não demonstraram atividade da $P K C \alpha^{42}$. A ativação da PKC induz a fosforilação e a ativação do complexo inibidor do fator nuclear kappa-B alfa quinase (complexo IאB- $\alpha$ quinase), responsável pela fosforilação do inibidor do fator nuclear kappa-B (IKB- $\alpha)$, levando este à ubiquitinação e à subseqüente degradação pelo sistema proteossômico. A degradação do $1 \kappa B-\alpha$ libera o fator nuclear kappa-B (NF-кB), que agora pode seguir ao núcleo celular e se ligar a regiões específicas levando à expressão gênica ${ }^{41,42}$. Esse evento está relacionado ao aumento da concentração de proteínas do sistema ubiquitina proteossoma ATP-dependente ${ }^{40}$. O PIF induz a diminuição do $1 \kappa B \alpha$ citosólico e o aumento da ligação do NFKB ao seu receptor nuclear, fato relacionado ao aumento da atividade de vias proteolíticas. Esse efeito foi atenuado por inibidores de PKC. Isto sugere que a PKC está 
envolvida na fosforilação e na degradação do $1 \kappa B \alpha$, induzida pelo PIF, necessário para liberação do NFkB do seu complexo citosólico inativo ${ }^{42}$. Várias vias envolvendo o NF-kB são ativadas por múltiplos estímulos extracelulares, levando à fosforilação e à subseqüente degradação de proteínas inibitórias, exemplo: IKB $\alpha^{41,42}$.

O HMB na concentração de $50 \mu \mathrm{mol} / \mathrm{L}$ atenua, efetivamente, a degradação do $1 \kappa B-\alpha$ em presença do PIF em miotúbulos de roedores, impedindo o acúmulo de NF- $\mathrm{KB}^{41}$. Dessa maneira, as vias de expressão de proteínas do proteossoma, de inibição da síntese protéica e do reparo celular são atenuadas pela presença do HMB, diminuindo o desbalanço no metabolismo protéico muscular (Figura 1).

\section{ONCLUSÃ O}

A suplementação com o metabólito do aminoácido leucina, conhecido como HMB, ainda possui eficácia discutível dependendo do resultado pretendido e da população na qual será aplicada. Em indivíduos iniciantes em treinamento de força os resultados parecem ser favoráveis ao aumento de massa isenta de gordura e força muscular, contudo em estudos que utilizaram atletas e indivíduos treinados não foi demonstrado efeito significativo da suplementação durante os períodos analisados. Diferentemente do observado em atletas, a administração de HMB a indivíduos idosos ou em situação patológica de hipercatabolismo muscular, provocou efeitos importantes sobre ganho ou preservação da massa isenta de gordura. Os

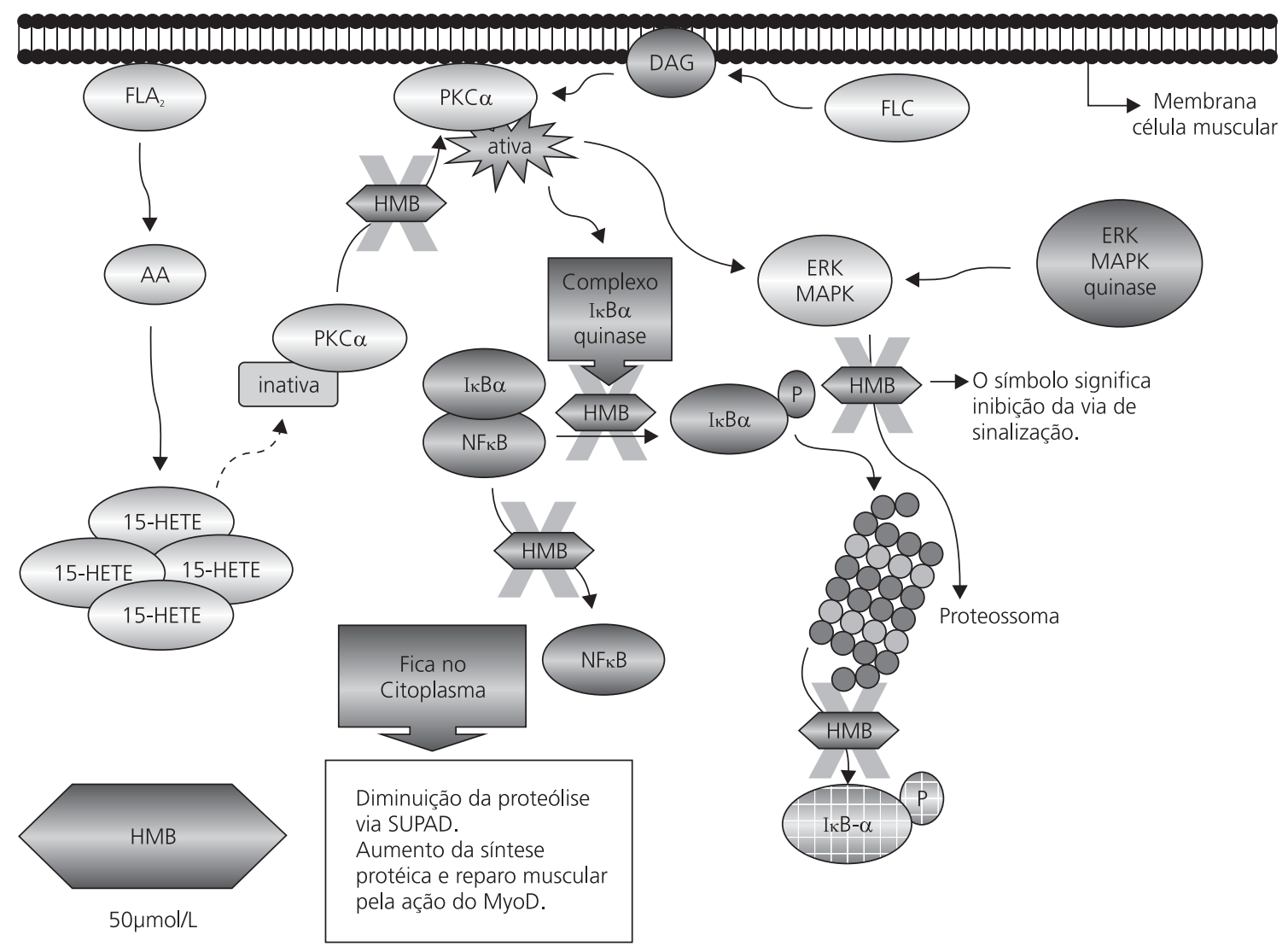

Figura 1. Efeito inibitório do $\beta$-hidroxi- $\beta$-metilbutirato $(\mathrm{HMB})$ sobre vias responsáveis pela proteólise em células musculares esqueléticas

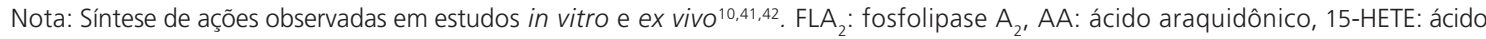
15 - hidroxi-eicosatetraenóico, PKC $\alpha$ : proteína quinase C-alfa; І $\kappa B \alpha$ : inibidor do fator nuclear kappa-B; NF-кB: fator nuclear kappa-B; DAG: diacilglicerol; FLC: fosfolipase C, ERK/MAPK: proteína quinase ativada por mitógeno; Proteossoma: proteossoma 26S; SUPAD: sistema ubiquitina proteossoma ATP-dependente. 
mecanismos de ação do HMB sobre o metabolismo muscular envolvem ação inibitória sobre vias de sinalização da PKC $\alpha$ e NF-אB, e sobre sistemas que induzem a proteólise no tecido muscular esquelético, em especial sobre o sistema ubiquitina proteossoma ATP-dependente. Em suma, o HMB tem ação anti-catabólica demonstrada em modelos animais, restando identificar os completos mecanismos de ação e averiguar se estes resultados também se repetem em humanos com a mesma magnitude.

\section{COLABORADORES}

E.A. NUNES foi responsável pela seleção dos trabalhos e pela divisão dos tópicos presentes na revisão. O desenvolvimento dos tópicos discutidos foi realizado pelos dois autores. L.C. FERNANDES fez a revisão crítica do manuscrito.

\section{REFERÊ NCIAS}

1. Kreider RB, Almada AL, Antonio J, Broeder C, Earnest C, Greenwood M, et al. International society of sports nutrition exercise \& sport nutrition review: research \& recommendations. Sports Nutr Rev J. 2004; 1(1):1-44.

2. Nissen SL, Sharp RL. Effect of dietary supplements on lean mass and strength gains with resistance exercise: a meta-analysis. J Appl Physiol. 2003; 94(2):651-9.

3. Biolo G, Tessari P, Inshiostro S, Bruttomesso C, Fongher C, Sabadin L, et al. Leucine and phenylalanine kinetics during mixed meal ingestion. A multiple tracer approach. Am J Physiol. 1992; 262(4Pt1):E455-E63

4. De Feo P, Horber PFF, Haymond MW. Meal stimulate albumin synthesis: a significant contributor to whole body protein synthesis in humans. Am J Physiol. 1992; 263(4Pt1):E794-9.

5. Gautsch TA, Anthony JC, Kimball SR, Paul GL, Layman DK, Jefferson LS. Eukaryotic initiation factor 4E availability regulates skeletal muscle protein synthesis during recovery from exercise. Am J Physiol. 1998; 274(2Pt1):C406-C14.

6. Anthony JC, Lang $\mathrm{CH}$, Crozier SJ, Anthony TG, MacLean DA, Kimball SR, et al. Contribution of insulin to the translational control of protein synthesis in skeletal muscle by leucine. Am J Physiol Endocrinol Metabol. 2002; 282(5):E1092-E01.

7. Anthony JC, Anthony TG, Kimball SR, Jefferson LS. Signaling pathways involved in translational control of protein synthesis in skeletal muscle by leucine. J Nutr. 2001; 131(3):856S-60S.

8. Shah OJ, Anthony JC, Kimball SR, Jefferson LS. Glucocorticoids oppose translational control by leucine in skeletal muscle. Am J Physiol Endocrinol Metabol. 2000; 279(5):E1185-E90.

9. Ostaszewski P, Kostiuk S, Balasinska M, Jank M, Papet I, Glomot F. The leucine metabolite 3-hydroxy3methylbutyrate (HMB) modifies protein turnover in muscles of laboratory rats and domestic chickens in vitro. J Anim Physiol Anim Nutr. 2000; 84:1-8.

10. Smith HJ, Mukerji P, Tisdale MJ. Attenuation of proteosome-induced proteolysis in skeletal muscle by $\beta$-hydroxy- $\beta$-methylbutyrate in cancer-induced muscle loss. Cancer Res. 2005; 65(1):277-83.

11. Nissen SL, Abumrad NN. Nutritional role of the leucine metabolite $\beta$-hydroxy- $\beta$-methylbutyrate (HMB). Nutr Biochem. 1997; 8:300-11.

12. Wiley DB, Dobbins TA. Composition and method for enhancing the bioavailability of calcium and magnesium in dietary supplements and food additives. United States Patent. 2004; 20040220266.

13. Van Koevering M, Nissen S. Oxidation of leucine and alpha-ketoisocaproate to beta-hydroxy-betamethylbutyrate in vivo. Am J Physiol. 1992; 262(1 Pt 1):E27-31.

14. Gallagher PM, Carrithers JA, Godard MP, Schulze KE, Trappe SW. Beta-hydroxy-beta-methylbutyrate ingestion, part II: effects on hematology, hepatic and renal function. Med Sci Sports Exerc. 2000; 32(12):2116-9.

15. Peterson AL, Qureshi M A, Ferket PR, Fuller JC Jr. Enhancement of cellular and humoral immunity in young broilers by the dietary supplementation of $\beta$-hydroxy- $\beta$-methylbutyrate. Immunopharm Immunotoxicol. 1999; 21(2):307-30.

16. Baxter JH, Carlos JL, Thurmond J, Rehani RN, Bultman J, Frost D. Dietary toxicity of calcium b-hydroxy-b-methylbutyrate (CaHMB). Food and Chem Toxicol. 2005; 43(12):1731-41.

17. Nissen S, Sharp RL, Panton L, Vukovich M, Trappe S, Fuller JC Jr. Beta-hydroxy-beta-methylbutyrate (HMB) supplementation in humans is safe and may decrease cardiovascular risk factors. J Nutr. 2000; 130(8):1937-45.

18. Crowe MJ, O'Connor DM, Lukins JE. The effects of beta-hydroxy-beta-methylbutyrate (HMB) and $\mathrm{HMB} /$ creatine supplementation on indices of health in highly trained athletes. Int J Sport Nutr Exerc Metab. 2003; 13(2):184-97.

19. Vukovich MD, Slater G, Macchi MB, Turner MJ, Fallon K, Ratchmacher J. $\beta$-hydroxy- $\beta$-methylbutyrate $(\mathrm{HMB})$ kinetics and the influence of glucose ingestion in humans. J Nutr Biochem. 2001; 12(11):631-9. 
20. Gallagher PM, Carrithers JA, Godard MP, Schulze KE, Trappe SW. $\beta$-hydroxy- $\beta$-methylbutyrate ingestion, Part I: effects on strength and fat free mass. Med Sci Sports Exerc. 2000; 32(12):2109-15.

21. Nissen S, Sharp R, Ray M, Rathmacher JA, Rice D, Fuller JC Jr, et al. Effect of leucine metabolite beta-hydroxy-beta-methylbutyrate on muscle metabolism during resistance-exercise training. J Appl Physiol. 1996; 81(5):2095-104.

22. Vukovich MD, Stubbs NB, Bohlken RM. Body composition in 70-year-old adults responds to dietary beta-hydroxy-beta-methylbutyrate similarly to that of young adults. J Nutr. 2001; 131(7): 2049-52.

23. Panton LB, Rathmacher JA, Baier S, Nissen S. Nutritional supplementation of the leucine metabolite beta-hydroxy-beta-methylbutyrate (HMB) during resistance training. Nutrition. 2000; 16 (9):734-9.

24. Ransone J, Neighbors K, Lefavi R, Chromiak J. The effect of beta-hydroxy beta-methylbutyrate on muscular strength and body composition in collegiate football players. J Strength Cond Res. 2003; 17(1):34-9.

25. Slater $G$, Jenkins $D$, Logan $P$, Lee $H$, Vukovich M, Rathmacher JA, et al. Beta-hydroxy-betamethylbutyrate (HMB) supplementation does not affect changes in strength or body composition during resistance training in trained men. Int J Sport Nutr Exerc Metab. 2001; 11(3):384-96.

26. Kreider RB. Dietary supplements and the promotion of muscle growth with resistance exercise. Sports Med. 1999; 27(2):97-110.

27. O'Connor DM, Crowe MJ. Effects of beta-hydroxybetamethylbutyrate and creatine monohydrate supplementation on the aerobic and anaerobic capacity of highly trained athletes. J Sports Med Phys Fitness. 2003; 43(1):64-8.

28. Paddon-Jones $D$, Keech $A$, Jenkins $D$. Short-term beta-hydroxy-beta methylbutyrate supplementation does not reduce symptoms of eccentric muscle damage. Int J Sport Nutr Exerc Metab. 2001; 11(4): 442-50.

29. Hoffman JR, Cooper J, Wendell M, Im J, Kang J. Effects of beta-hydroxy beta-Methylbutyrate on power performance and indices of muscle damage and stress during high-intensity training. J Strength Cond Res. 2004; 18(4):747-52.

30. Flakoll P, Sharp R, Baier S, Levenhagen D, Carr C, Nissen S. Effect of betahydroxy- beta-methylbutyrate, arginine, and lysine supplementation on strength, functionality, body composition, and protein metabolism in elderly women. Nutrition. 2004; 20(5):445-51.

31. Knitter AE, Panton L, Rathmacher JA, Petersen A, Sharp R. Effects of beta-hydroxy-beta-methylbutyrate on muscle damage after a prolonged run. J Appl Physiol. 2000; 89(4):1340-4.

32. May PE, Barber A, D'Olimpio JT, Hourihane A, Abumrad NN. Reversal of cancer-related wasting using oral supplementation with a combination of beta-hydroxy-beta-methylbutyrate, arginine, and glutamine. Am J Surg. 2002; 183(4):471-9.

33. Clark RH, Feleke G, Din M, Yasmin T, Singh G, Khan $F A$, et al. Nutritional treatment for acquired immunodeficiency virus-associated wasting using beta-hydroxy beta-methylbutyrate, glutamine, and arginine: a randomized, doubleblind, placebocontrolled study. J Parenter Enteral Nutr. 2000; 24(3):133-9.

34. Jowko E, Ostaszewski P, Jank M, Sacharuk J, Zieniewicz A, Wilczak J, et al. Creatine and betahydroxy-beta-methylbutyrate (HMB) additively increase lean body mass and muscle strength during a weight-training program. Nutrition. 2001; 17(7-8):558-66.

35. Marcora S, Lemmey A, Maddison P. Dietary treatment of rheumatoid cachexia with b-hydroxyb-methylbutyrate, glutamine and arginine: a randomized controlled trial. Clin Nutr. 2005; 24(3):442-54.

36. Kuhls DA, Rathmacher JA, Musngi MD, Frisch DA, Nielson J, Barber A, et al. Beta-hydroxy-betamethylbutyrate supplementation in critically ill trauma patients. J Trauma. 2007; 62(1):125-31.

37. Lecker SH, Solomon V, Mitch WE, Goldberg AL. Muscle protein breakdown and the critical role of the ubiquitin-proteasome pathway in normal and disease states. J Nutr. 1999; 129(1S-Suppl): 227S-37S.

38. Goll DE, Thompson VF, Taylor RG, Christiansen JA. Role of the calpain system in muscle growth. Biochemie. 1992; 74(3):225-37.

39. Lorite MJ, Thompson MG, Drake JL, Carling G, Tisdale MJ. Mechanism of muscle protein degradation induced by a cancer cachectic factor. Br J Cancer. 1998; 78(7):850-6.

40. Tisdale MJ. The ubiquitin-proteasome pathway as a therapeutic target for muscle wasting. J Support Oncol. 2005; 3(3):209-17.

41. Smith HJ, Wyke SM, Tisdale MJ. Mechanism of the attenuation of proteolysis-inducing factor stimulated protein degradation in muscle by $\beta$-hydroxy- $\beta$ methylbutyrate. Cancer Res. 2004; 64(23):8731-35.

42. Smith HJ, Wyke SM, Tisdale MJ. Role of Protein Kinase $\mathrm{C}$ and NF-kB in proteolysis inducing factor induced proteossome expression in C2C12 myotubes. Br J Cancer. 2004; 90(9):1850-7.

Recebido em: 24/10/2006

Versão final reapresentada em: 26/10/2007 Aprovado em: 15/2/2008 